IFN Working Paper No. 791, 2009

\title{
The Burden of Proof in National Treatment Disputes and the Environment
}

Henrik Horn 


\title{
The Burden of Proof in National Treatment Disputes and the Environment
}

\author{
Henrik Horn ${ }^{1}$ \\ The Research Institute of Industrial Economics (IFN), Stockholm \\ Bruegel, Brussels \\ Centre for Economic Policy Research, London
}

April 13, 2009

\footnotetext{
${ }^{1}$ I am very grateful for extremely helpful discussions with Petros C. Mavroidis. I would also like to thank Erik Lindqvist, Lars Persson, and participants in the Environment and Trade in a World of Interdependence (ENTWINED) research consortium 2009 Burgundy Meeting for useful comments, and Christina Lönnblad for editorial assistance. Financial support by the Marianne and Marcus Wallenberg Foundation, and Mistra (Stockholm) is gratefully acknowledged. Contact: henrik.horn@econ-law.se; ph: +46 70 7428839; fax: +468 6654599
} 


\section{Contents}

1 Introduction $\quad 3$

2 The Burden of Proof in GATT/WTO NT Disputes $\quad 8$

3 The Model $\quad 10$

$\begin{array}{llr}\text { Tax Setting } & 17\end{array}$

5 Tariff Negotiations $\quad 19$

5.1 NT Binds for Both Types of Governments . . . . . . . . . . . . . . . . . 21

5.2 NT Only Binds for Environmentally Affected Governments . . . . . . . . . 23

6 The Impact of the BoP $\quad 24$

6.1 The BoP and Global Welfare . . . . . . . . . . . . . . 25

6.2 The BoP and Negotiated Tariffs . . . . . . . . . . . . . . . . . . . . 26

6.3 The BoP and Environmental Damage . . . . . . . . . . . . . 28

7 The Costs of Environmental Shocks $\quad 30$

8 Extensions $\quad 31$

8.1 Litigation Costs . . . . . . . . . . . . . . . . . . . . . . . . . . . . . .

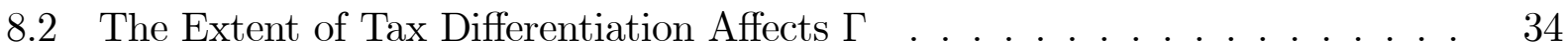

8.3 More Sophisticated Adjudicators . . . . . . . . . . . . . . 35

9 Conclusions $\quad 36$ 


\title{
The Burden of Proof \\ in National Treatment Disputes and the Environment
}

by

Henrik Horn

\begin{abstract}
This paper examines the role of the burden of proof $(\mathrm{BoP})$ in National Treatment (NT) disputes under trade agreements. In the situation under study, imports may cause environmental damage, in which case less favorable treatment of imported products may be globally desirable from an international efficiency point of view. But adjudicators do not with full certainty know the motives for policies that are allegedly pursued to protect the environment, but that also give commercial advantages to domestic products. The paper points to a tension between NT and environmental concerns, in that NT will primarily target countries exposed to environmental shocks. But contrary to what might be expected, this tension is not likely to arise when the environmental threats are very severe. The paper also shows why a shift of the BoP in environmental disputes toward complaining (exporting) countries will not necessarily reduce the environmental damage in importing countries.
\end{abstract}

JEL classification: Q56, F13

Keywords: National treatment, burden of proof, environment, GATT, WTO, trade agreements 


\section{Introduction}

A constant source of controversy in the environment and trade policy debate is the World Trade Organization's (WTO) alleged tendency to prevent members from pursuing national environmental policies. Some observers see WTO disputes such as US-Shrimp, EC-Hormones and EC-Biotech Products (the "GMO dispute") as indications of a trade regime that is intrinsically unfriendly toward the environment. While at least occasionally accepting the possibility that protectionist policies may be disguised as protecting the environment, these critics often seem to suggest that countries claiming to pursue environmental objectives should enjoy the benefit of the doubt in WTO disputes to a larger degree than they currently do. Other observers instead maintain that the agreement leaves ample scope for members to pursue whatever policies they like, including environmental policies, as long as they do not apply these policies in a protectionist fashion.

What is clear is that there is a number of provisions in the WTO Agreement that, depending on the interpretation, could potentially interfere with the pursuit of national environmental policies. The basic potential obstacle in this regard is the National Treatment (NT) provision in Art. III of the General Agreement on Tariffs and Trade (GATT), which broadly speaking requests countries to pursue their domestic policies affecting goods trade environmental policies included - in a non-discriminatory fashion; that is, foreign products should not in a protectionist fashion be treated less favorably than similar domestic products. Provisions with similar wording or spirit can also be found in several of the other agreements in the WTO Agreement. ${ }^{1}$

Broadly speaking, the role of NT is to prevent members from undermining tariff concessions through the use of domestic instruments. For instance, a domestic tax on an imported product could essentially have the same impact as an import tariff, so it would be meaningless to bind the tariff if it could simply be replaced by a domestic tax. Therefore, trade

\footnotetext{
${ }^{1}$ Examples are the Agreement on Sanitary and Phytosanitary Measures (SPS), the Agreement on Technical Barriers to Trade (TBT), and the General Agreement on Trade in Services (GATS).
} 
agreements cannot include constraints on the use of border instruments only, but must also restrict the use of domestic policy instruments. ${ }^{2}$ The problem is however, that domestic instruments can take an endless variety of forms. There is also a huge number of different circumstances in which they could be used, sometimes for what members would consider to be legitimate purposes, such as to protect the environment, and sometimes for purposes that are only unilaterally rational. Therefore, it would be prohibitively costly to directly bind all domestic instruments in an adequate fashion. Virtually all trade agreements escape the contracting problem by including the very simple NT principle that domestic instruments must not be used to give domestic products more favorable treatment than like foreign products. At the same time, the law recognizes that it may sometimes be desirable to let members treat imports less favorably. In the WTO, this is manifested in the vague notion that Art. III GATT is concerned with measures that are "applied so as to afford protection." And the general exceptions clause in Art. XX allows countries to pursue e.g. environmental policies that violate Art. III GATT, provided that they are "necessary" and not "disguised protection."

The general idea concerning domestic measures is thus to weed out those that are protectionist while at the same time allow measures that are in some sense desirable. The fundamental problem facing this sorting of the wheat from the chaff is the fact that adjudicators cannot directly observe the objectives that are being pursued through the contested policies - indeed, if they could, there would be no need for NT in the first place. Instead, adjudicators must rely on evidence presented by the parties concerning the nature of the contested policies. A central mechanism for controling the evaluation of such evidence, and hence the bite of the legal text, is the distribution of the burden of proof $(\mathrm{BoP})$ between complainants and respondents. For instance, it seems intuitively plausible that it will make

\footnotetext{
${ }^{2}$ Note, though, that the purpose of the GATT is not to prevent protection as such. Instead, the purpose is to channel all protection through one type of policy instrument - import tariffs - and let the level of protection be negotiated, thus forcing the benefits and costs of protective measures to be indirectly weighted against each other.
} 
a very significant difference to the expected outcome of environmental disputes if exporting countries when acting as complainants have to show that challenged environmental measures amount to "protection," or if instead importing countries have to prove that their measures do not amount to protection. The purpose of this paper is to highlight some core implications of the allocation of the BoP in environmental NT disputes.

The paper develops a two-country, partial equilibrium trade model. In the first stage of their interaction, governments negotiate a contractually incomplete agreement, which binds tariffs but leaves taxes to be set unilaterally, although constrained by an NT-type restriction. Countries are then possibly subjected to environmental shocks that emanate from imports and, having privately observed these shocks, countries unilaterally determine domestic taxes for imported and locally produced goods. These shocks may be sufficiently severe for trade restrictions to be desirable also from a global point of view, despite the fact that there are also always protectionist motives for the restrictions. The unilaterally set taxes may, in a final stage, be legally challenged in a trade dispute, in which case an adjudicator determines the legality of the contested measure. The adjudicator is imperfectly informed about the true motives for the measure and therefore cannot determine with certainty whether it is desirable from a global efficiency point of view. But the adjudicator is less likely to accept a complaint when the importing country has been environmentally affected. However, judicial mistakes will be committed in that governments will sometimes be allowed to differentiate in their taxation between domestic and imported products, despite the fact that the tax distinctions solely express protectionism and, in other instances, governments will have to remove differential taxation schemes even though they are globally desirable. A central determinant of the propensity to make such mistakes is the allocation of the BoP. The more specific purpose of the paper is to determine the role of the distribution of this burden for negotiated tariffs, the nature of judicial mistakes, global welfare and environmental damage from imports.

Despite the highly stylized character of the model, several observations emerge that seem 
to be of more general validity. A first general conclusion is that there may be a tension between NT, as it is likely to be implemented in the WTO, and environmental concerns. More specifically, whenever trade liberalization has gone sufficiently to induce at least some countries to set domestic taxes that violate NT, it will always apply to governments facing environmental shocks, but not necessarily to purely protectionist governments. NT in this sense starts to bind from the wrong side of the spectrum of government types, since environmentally affected governments will have stronger reasons for differentiating their taxation to the detriment of imported products; these governments will have the same protectionist desires as other governments and, in addition, they will have environmental reasons for taxing imported products higher than domestic products.

Second, adjudicators will sometimes, due to judicial errors, not allow importing countries that are exposed to an environmental hazard from imported products to tax imported products more than they tax domestic products. Such judicial mistakes will obviously be associated with welfare costs. However, contrary to what might at first be expected, when the environmental hazards are sufficiently severe, such judicial mistakes will actually not have any environmental impact, but will instead take the form of lost consumer and producer surplus. The reason is that a core feature of NT is that it always leaves discretion to the importing country over the common policy treatment of imported and domestic products. The importing country will in case of a significantly severe environmental shock from imports, use this discretion to shut out all imports and thus all environmental damage. The cost might, however, be that in the process, it also has to shut down the whole (environmentally friendly) domestic industry producing the like product.

The third more general finding is that a shift of the burden of proof toward complaining (exporting) countries is no panacea for reducing environmental damage from imports. Such a shift will have a positive direct effect, by reducing the number of disputes in which NT is wrongfully imposed. But it will also affect the negotiated tariff - this is indeed the purpose of NT in the first place. The direction of this change is not clear a priori. But if it lowers 
the tariff, as seems plausible, this shift in the BoP will tend to increase imports and will thus tend to increase the environmental damages connected with imports.

Turning to the related literature, it can be noted that there are very few studies examining the interaction between some form of NT rule with regard to tariff negotiations and domestic taxation in general, despite the fact that the rationale for the provision is to provide incentives for countries to make tariff concessions. ${ }^{3}$ Several studies consider the impact of some form of NT provision for the use of environmental standards, assuming that tariff levels are exogenous. ${ }^{4}$ But, to the best of our knowledge, this paper is the first to formally examine the role of the allocation of the BoP in environmental NT disputes, and more generally analyze implications of NT in a setting where adjudicators are uncertain about government motives.

The study of the implications of a Most-Favored Nation (MFN) clause in [6] is closely related to this paper in certain respects. MFN differs from NT in that MFN restricts the extent to which members can apply different policies (notwithstanding if border or domestic instruments) to products from different exporting countries, while NT instead restricts the extent to which countries can favor domestic products over imported products using domestic instruments (by definition, border instruments favor domestic products, but are bound). Hence, both papers seek to highlight environmental implications of one of the two non-discrimination provisions that form the core of the GATT and the WTO regimes. But the papers also differ significantly. For instance, much of the focus in [6] is on multilateral environmental agreements, whereas the focus here is on judicial errors in adjudication processes under a trade agreement. ${ }^{5}$ Somewhat related to the present paper is also the literature on

\footnotetext{
${ }^{3}$ To the best of our knowledge, this is only done in elementary form in [1], in much more detail in [2], and using a framework in which the structure of the agreement (including NT) is endogenously determined, in [3].

${ }^{4}$ Recent examples are [4] and [5].

${ }^{5}$ Most politically charged disputes that have been adjudicated in the WTO have centered on NT rather than MFN. But there is no doubt that MFN may become a central issue in future environmental disputes, not least with regard to the enforcement of multilateral environmental agreements.
} 
imperfect monitoring in trade agreements, which analyzes the role of different types of dispute settlement institutions in trade agreements. A recent example of this strand of this literature is [7], which assumes that adjudication is made with error. But the focus in [7] is not on environmental issues, nor on the role of the BoP in NT disputes, or on the impact of the distribution of the BoP for the incentives to reduce tariffs, which are the issues at the core of interest here. There are also certain points of tangency between the current paper and the discussion in [8] concerning whether trade agreements should include environmental provisions in cases where environmental externalities are non-transboundary.

The structure of the rest of the paper is as follows. Section 2 briefly discusses some salient features of the BoP in NT disputes in the WTO. Section 3 presents the model of the economy and of adjudication. Section 4 derives unilaterally optimal taxes. Tariff negotiations are considered in Section 5. Section 6 examines the impact of the BoP. Section 7 briefly examines the nature of the costs from environmental shocks. Section 8 discusses some possible alternative assumptions to those made in the paper and Section 9 summarizes the main findings.

\section{The Burden of Proof in GATT/WTO NT Disputes}

The core NT provision in the WTO regulating domestic taxation is Art. III.2 GATT, which states that imported products must not be taxed "in excess" of domestic "like" products. ${ }^{6}$ There is also an amorphous statement in Art. III.1 GATT that sets the sight of Art.III on measures that are "applied so as to afford protection." Thus, there is a fundamental tension in Art. III GATT between, on the one hand, the clear obligation with regard to how to use domestic taxes in Art. III.2 and, on the other hand, the vague but necessary restriction of

\footnotetext{
${ }^{6}$ There is also a second category of product pairs, with somewhat different rules, which are disregarded here - "directly competitive or substitutable" product pairs. More generally, the description of the text and the case law is, for space reasons, extremely rudimentary. See [9] for a more thorough presentation of Art. III.2 GATT, and for an evaluation of its case law.
} 
the ambit in Art. III.1.

If in an environmental dispute, a measure is found to violate Art. III GATT, the respondent will almost automatically take recourse to Art. XX GATT. This article contains general grounds for exceptions from any other provision in the agreement. It essentially states that members are free to do what is "necessary to protect human, animal or plant life or health," provided that this does not constitute "a disguised restriction on international trade." Hence, just as in Art. III.1 GATT, the avoidance of disguised protection is an essential component.

There are two firmly established general principles for allocating the BoP in GATT/WTO disputes. One is that the party claiming a violation carries the burden of production to provide (prima facie) evidence for its claim; the other is that the party claiming an exception carries the burden of production to show eligibility for the exception. ${ }^{7,8}$ The concept of prima facie evidence seems to have limited practical meaning in the WTO context, however. There is no initial stage where the adjudicating body determines whether a complaint will be heard; on the contrary, each member has the right to pursue whatever dispute the member wants. Instead, at the end of dispute proceedings, courts typically weigh the totality of the evidence presented before them to determine whether the complainant or the respondent has amassed relatively more evidence.

The dominating approach in Art. III.2 GATT case law has been to impose the burden of production on the complainant to show that taxation is "in excess," but the associated burden of persuasion for this has been quite light. If an importing country is found to violate Art. III.2, and therefore seeks an Art. XX exception, it carries the burden, in particular, to show that the measure is not "disguised protection," and that it is "necessary." The burden of persuasion for this is likely to be rather high. This mode of allocating the BoP hence puts much of the BoP on the regulating country. But it has been suggested (at least implicitly)

\footnotetext{
${ }^{7}$ The burden of production specifies the identity of the party that will lose the dispute if no evidence is brought forward. The burden of persuasion specifies the amount of evidence required to fulfill the burden of production.

${ }^{8}$ See [10] for an analysis of the treatment of the BoP in case law of relevance to environmental disputes.
} 
that more of a burden should be put on the complaining country. This could be done e.g. by requiring the complainant to demonstrate that a contested measure amounts to "disguised protection," for an Art. XX exception not to be automatically granted for an environmental measure.

A core issue for the allocation of the BoP in NT disputes is to balance the incentives for countries to reduce their impediments to trade against the possibility to pursue legitimate regulations even if they result in higher taxation of foreign than of domestic products. Since the parties will not be able to provide the adjudicators with full information concerning the circumstances of the respective disputes, judicial errors will inevitably be committed, and it would seem as if some of these errors have the potential of leading to significant environmental damage. The design of the BoP system must therefore weigh the costs of false positive findings of violations (Type I errors) against the costs of erroneous acquittals (Type II errors) while, at the same time, taking into consideration the benefits from making tariff liberalization commitments meaningful. The analysis to follow is intended to shed some light on this trade-off. ${ }^{9}$

\section{The Model}

Consider a two-country, two-sector, partial equilibrium model. In one sector, Home produces a good and imports a close substitute - a "like" product - from Foreign. The other sector is a mirror image where Home exports to Foreign. The Home government levies an import

\footnotetext{
${ }^{9}$ The Law and Economics literature also points to several other aspects of the BoP. For instance, a common theme is that the system should be designed so as to minimize the legal costs. As will be argued in Section 8, such costs could have a significant qualitative impact on the interaction between (potential) complainants and respondents. A second recurrent theme in the literature is that the optimal distribution of the BoP needs to take into consideration the distribution of information across parties. In particular, it is commonly found that the BoP should be put on the better informed party; see e.g. [11] for a formal analysis along these lines, and [12] for a different view.
} 
tariff $\tau$, and internal taxes $r$ and $s$, where $r$ is the tax on the domestic product, and $s$ the tax on the imported product. ${ }^{10}$ The total tax burden on the imported product is thus $t=s+\tau$. For simplicity, the market structure is assumed to be perfectly competitive, but the analysis to follow would also be compatible with other structures.

Government welfare is separable into three components. For the Home government, welfare is

$$
Y(r, t)+\Pi\left(r^{*}, t^{*}\right)-\theta M(r, t) .
$$

The first component, $Y(r, t)$, consists of consumer and producer surplus in the domestic market, and government revenue; these components are jointly denoted by $Y(r, t)$. The exact way in which these components enter is immaterial, and could thus encompass "political" considerations, such as when there is a larger weight on producer surplus than on consumer surplus.

The second component of government welfare derives from export sales $\Pi$. This could be the producer surplus that is generated, the employment in the export sector, etc, but for simplicity, we will will refer to this as export sales. This component will depend on Foreign total taxes $r^{*}$ and $t^{*}=s^{*}+\tau^{*}$ levied by the Foreign country; hence, $\Pi=\Pi\left(r^{*}, t^{*}\right)$. All that is assumed is that the export sales are higher, the higher is the tax on the domestic product $r^{*}$, and the lower is the total tax on the imported product $t^{*}$, and an equal increase in $r^{*}$ and $t^{*}$ reduces export sales: $\frac{d}{d z} \Pi^{*}(z, z)<0$.

The third component of government welfare stems from the environmental impact of the imported Foreign product. $M(r, t)$ denotes the import volume, which increases in the tax on the domestic product, and falls in the total taxation of the imported product $\left(M_{r}>0\right.$ and $\left.M_{t}<0\right)$. The adverse environmental impact of imports is then given by $-\theta M(r, t)$, where $\theta$ is a stochastic parameter capturing the intensity of the environmental problem. If sufficiently

\footnotetext{
${ }^{10}$ Following much of the partial equilibrium literature on trade agreements, we assume that countries do not have access to export taxes.
} 
severe, this environmental shock provides an efficiency-based rationale for higher taxation of the imported product and thus, a reason why the trade agreement does not just simply request laissez-faire. For the sake of analytical simplicity, it is assumed that the effect of this environmental shock is only experienced in the importing country.

This highly stylized structure is compatible with several familiar scenarios where imported products may lead to environmental hazards. For instance, the environmental problem could stem from a negative consumption externality in the importing country, such as when asbestos-containing construction materials are imported. The uncertainty could then either concern the state of scientific knowledge about the extent to which asbestos is dangerous for health, or it could reflect changes in the domestic policy debate. Or it could capture the exportation of beef from cattle that has received growth hormones to enhance production, and where it is uncertain whether consuming such beef is dangerous to human health, or where there are changes in popular opinion concerning such effects. The externalities may also arise in connection with the transportation of the product, or in connection with production in the exporting country, if the effects travel to the importing country. These scenarios seem highly plausible. What is admittedly somewhat special for some of these scenarios is the assumption that the exporting country is not affected by the realization of $\theta$. But this could either be motivated by the assumption that the environmental effects are not felt in the exporting country, such as in the case of acid rain that travels to other countries, or toxic waste that is dumped into a river that flows into another country. Alternatively, it could be the case that the exporting country government is oblivious to the environmental impact. For instance, the importing country may be concerned with the effect of the production of imports on climate warming, while the government in the exporting country does not believe in such a link, sees no political gains from acting, or benefits from climate warming. However, we do not want to push the generality of these scenarios too far. After all, the assumption that the effects are only felt locally in the importing country is made for analytical convenience. It could straightforwardly be relaxed, but it seems as if little additional insight would be won 
from doing this, as long as the possibility of an agreement on the environment is not brought into the picture. The latter would definitely be an interesting exercise, but it would be the topic of another paper. ${ }^{11}$

It will prove convenient for what follows to define the function $V\left(r, t ; \theta_{i}\right) \equiv Y(r, t)-$ $\theta M(r, t)$, which thus comprises those matters of policy concern for Home that it can affect through its own policies. To ensure a role for NT in a trade agreement, $V$ is assumed to be strictly concave, and it is assumed that the taxes $r^{\prime}$ and $t^{\prime}$ that maximize $Y(r, t)$ have the property that $0 \leq r^{\prime}<t^{\prime}$, that is, that Home has a unilateral incentive to tax the imported product higher than the domestic product, absent any environmental concerns. This formulation is general enough to allow the Home government objective to be standard social welfare maximization, or to be the maximization of some "political economy" objective (see [14]). With this definition of $V$, we can thus write Home government welfare as $V(r, t, \theta)+$ $\Pi\left(r^{*}, t^{*}\right)$. Given the symmetry of the two countries, it is natural to let global welfare be represented by the sum of the two governments' welfare. Due to the partial equilibrium analysis and the symmetry between the sectors, we can focus on the industry in which Home is an importer; an analysis of the other sector would be identical. Letting $W$ denote aggregate government welfare created in the Home market:

$$
W\left(r, s+\tau, \theta_{i}\right) \equiv V\left(r, s+\tau, \theta_{i}\right)+\Pi^{*}(r, s+\tau),
$$

where $\Pi^{*}(r, t)$ thus denotes the welfare that Foreign derives from its export sales to Home.

To summarize the model thus far: as in a standard trade model, governments have unilateral incentives to tax imports, for instance to improve their terms of trade. This can equally well be through a tariff or a domestic tax on imported products; if governments had no such incentives, there would not be any need for a trade agreement in the first place. When governments seek to unilaterally restrict trade, they exert negative externalities on the trading partner, and the outcome is globally inefficient. The basic role of the trade

\footnotetext{
${ }^{11}$ See [13] for a discussion of the permissible reach of national environmental policies under the WTO
} Agreement. 
agreement is to help countries out of this Prisoners' Dilemma-like situation. But matters are complicated by the fact that there may also be an environmental hazard associated with imports. When this hazard is significant enough, it may be desirable also from a global point of view to allow some taxation of the imported product. An efficient trade agreement needs to permit some form of trade restriction, should such a situation arise.

There is a fundamental difficulty for the design of the trade agreement, however, which is that the true magnitude of environmental shocks is not directly observable to outsiders. To capture this feature in a simple fashion, we assume that there are two types of governments, which differ in whether they experience an environmental shock. Governments of type $L$ experience no shock $\left(\theta_{L}=0\right)$, so their only reason for taxing imports is protectionism. Governments of type $H$ are hit by an adverse environmental shock $\theta_{H}>0$ associated with imports, which constitutes an additional reason for imposing higher total taxation on imports. However, the exposure to this shock does not remove the protectionist inclination that these governments share with governments of type $L$. As will be made more precise below, it is assumed that the $\theta_{H}$ is sufficiently large for it to be desirable also from a global efficiency point of view to set a higher total tax on the imported product than on the domestically produced good, for certain tariff levels. If this were not the case, the adjudication problem would be trivial, since it would be optimal to always forbid higher taxation of the imported product. On the other hand, governments of type $L$ clearly have no efficiency rationale for taxing imported products higher than domestic products.

The sequence of events is as follows:

1. governments agree on tariffs, and include an NT rule in their agreement;

2. governments privately observe their respective environmental shocks;

3. governments set taxes; and

4. exporting countries may litigate alleged violations of the NT provision. 
The NT provision stipulates that " $r<s$ is illegal if the taxation is applied so as to afford protection." If a dispute arises concerning whether a pair of taxes violates NT, the issue is determined by an arbitrator. The decision can either be that the complaint is justified, in which case the respondent must change its taxation such that $r \geq s$, or that the respondent prevails, in which case it maintains its original taxes.

The adjudicator can determine without error whether $r<s .{ }^{12}$ But in order to implement the provision, the adjudicator must also determine whether the measure is "applied so as to afford protection," which will have to be done on basis of imperfect information concerning the preferences that motivate the taxation and hence, also on basis of imperfect information concerning whether differential taxation enhances global welfare. We will not model the details of this decision making, which can be expected to often be highly complex in environmental disputes. To capture this, it is assumed that the outcome of adjudication - whether a measure $r<s$ is determined to be legal or illegal - is random. But the probability of the outcome depends on two important features of the situation at hand: whether the responding government has actually experienced an environmental shock, and the general stand on the BoP. Letting $\gamma$ denote the probability that the complainant (the exporting country) prevails, this probability can thus be expressed as

$$
\gamma=\left\{\begin{array}{l}
0 \text { for } r \geq s \\
\Gamma(\theta, b) \text { for } r<s
\end{array} .\right.
$$

To capture the notion that it is more likely that the complainant will prevail if the importing country government has not experienced an environmental shock, it is assumed that $0<$ $\Gamma\left(\theta_{H}, b\right)<\Gamma\left(\theta_{L}, b\right)<1$. Parameter $b$ is an index of the allocation of the BoP between the complainant and the respondent. A shift of the $\mathrm{BoP}$ toward the complainant is, indexed by an increase in $b$, defined as a measure that reduces the probability for the complainant of prevailing against both types of importing country governments (that is, $\Gamma_{b}\left(\theta_{i}, b\right)<0$ ).

\footnotetext{
${ }^{12}$ This is not an innocuous assumption when made to describe the GATT, given the highly amorphous term "indirect" in its Art. III.2.
} 
As an example of how the allocation of the BoP could be of importance in the context of the WTO, consider the notion "necessary" in the general exceptions clause Art. XX GATT. For the importing country to show that a contested measure is necessary, it would, in principle, have to show that in the universe of all possible measures, the chosen measure is the only one that could achieve the objective. This would not only be enormously timeconsuming, it would also place no limit on what other adjustments the importing country should consider, such as using other instruments to achieve this objective. ${ }^{13}$ While not going fully to this extreme, earlier case law did give the word "necessary" a rather literal interpretation. But more recent case law has added the notion of "reasonably available" to the term "necessary," in recognition of the fact that there should be some form of constraint on the domain of policies in which an alternative policy should be sought. These two approaches to the BoP are likely to have very different implications for the probability that an importing country could prevail in a dispute.

This formalization of the adjudication process rests on two highly simplifying assumptions, besides the informational assumptions mentioned above. One is that the probability of a complainant winning a case where $r<s$ is independent of the absolute magnitude $s-r$. The second assumption is that there are no litigation costs. These assumptions will be discussed in Section $8 .{ }^{14}$

\footnotetext{
${ }^{13}$ For instance, suppose that a country taxes an imported product that causes environmental harm higher than the like domestic product. Faced with an NT dispute, it argues that the measure is necessary to prevent environmental damage. But the exporting country could maintain that the tax differential is not necessary, since the importing country could impose a uniform tax on both products, and achieve the same objective, albeit at the cost of reducing local production that does not cause environmental harm. See [1] for an analysis of such an unlimited interpretation of "necessary".

${ }^{14}$ The information available to the adjudicator could easily be given a more explicit description also within the current approach. For instance, let $p$ be the adjudicator's probability assessment after the evidence has been presented that a pair $r<s$ is applied so as to afford protection. The burden of persuasion requires that $p \leq b$ in order for the adjudicator to determine in favor of the complainant. Let $p_{0}$ be the adjudicator's prior. Since the burden of production rests with the complainant, $b$ is sufficiently low relative to $p_{0}$ that
} 
To conclude, when governments negotiate tariffs, they take into consideration how these will affect future unilateral tax setting, as constrained by NT, and the occurrence of judicial mistakes. Our main concern is to determine how this process is affected by the allocation of the BoP and, in particular, whether from the point of view of global welfare and the environment, there are any reasons to put the burden solely on exporting countries.

\section{Tax Setting}

If unconstrained by NT, a Home government of type $i$ would choose the taxes solving

$$
\max _{r, t} V\left(r, t ; \theta_{i}\right)
$$

Denote the solution to this problem as $\hat{r}\left(\theta_{i}\right)$ and $\hat{t}\left(\theta_{i}\right)$. The tariff level will have no implication for the resulting total taxation of either of the products, since the tax on imported products will be implicitly defined by $\hat{s}\left(\tau, \theta_{i}\right) \equiv \hat{t}\left(\theta_{i}\right)-\tau$ for $\tau \leq \hat{t}\left(\theta_{L}\right)$; we disregard the opposite case since it seems implausible. Since the products are identical from a consumer point of view, it follows that $\hat{r}\left(\theta_{i}\right)<\hat{t}\left(\theta_{i}\right)$, reflecting the basic protectionist motive for any type of government. Furthermore, since a higher $\theta_{i}$ corresponds to a larger environmental shock from the imported product, $\hat{r}_{\theta_{i}}<0$, and $\hat{t}_{\theta_{i}}=\hat{s}_{\theta_{i}}>0$. Let $\hat{\tau}\left(\theta_{i}\right) \equiv \hat{t}\left(\theta_{i}\right)-\hat{r}\left(\theta_{i}\right) ; \hat{\tau}\left(\theta_{i}\right)$ is hence the tariff level at which the discretionary taxes just fulfil the NT rule, and $\hat{\tau}_{\theta}=\hat{t}_{\theta}-\hat{r}_{\theta}>0$. The resulting Home government welfare from the domestic market and the profits of Foreign are thus functions of $\theta_{i}$ only:

$$
\hat{v}\left(\theta_{i}\right) \equiv V\left(\hat{r}\left(\theta_{i}\right), \hat{t}\left(\theta_{i}\right), \theta_{i}\right) \quad \hat{\pi}^{*}\left(\theta_{i}\right) \equiv \Pi^{*}\left(\hat{r}\left(\theta_{i}\right), \hat{t}\left(\theta_{i}\right)\right)
$$

should no evidence at all be presented in the dispute proceeding, so that there is no updating of the prior and thus $p=p_{0}$, the complainant loses: $p_{0}>b$. Let $p_{0}+\rho(\theta)$ be the probability assessment after the parties have presented their arguments, where $\rho(\theta) \in[a,-a], 0<a<1$. It is not necessary to impose any particular assumptions on the distribution of this stochastic variable, except that $E\left(\rho\left(\theta_{H}\right)\right)>E\left(\rho\left(\theta_{L}\right)\right)$. (Naturally, for $\rho>0, p=\min \left(1, p_{0}+\rho\right)$, and for $\rho<0, p=\max \left(0, p_{0}+\rho\right)$.) With this formalization, we would have that $\Gamma(\theta, b) \equiv \operatorname{Pr}\left(p_{0}+\rho(\theta) \leq b\right)$. It appears as if such a formulation of the model would mainly add notational complexity, as long as the realization of $\rho$ is exogenous. 
If constrained to set NT-compatible taxes $r=s \equiv \bar{z}\left(\theta_{i}, \tau\right)$, Home would choose the tax level $\bar{z}\left(\tau, \theta_{i}\right)$ that solves

$$
\max _{z} V\left(z, z+\tau, \theta_{i}\right)
$$

The first-order condition defining $\bar{z}\left(\tau, \theta_{i}\right)$ is hence

$$
V_{r}\left(z, z+\tau, \theta_{i}\right)+V_{t}\left(z, z+\tau, \theta_{i}\right)=0
$$

where $V_{r}<0$ and $V_{t}>0$ in optimum. It follows that $-1<\bar{z}_{\tau}<0$, so an increase in the tariff is compensated by a reduction in the common tariff level, but it is of smaller magnitude than the tax increase, resulting in an overall increase in the total taxation of the imported product. The NT regime yields a Home government welfare in the domestic market of

$$
\bar{v}\left(\theta_{i}, \tau\right) \equiv V\left(\bar{z}\left(\tau, \theta_{i}\right), \bar{z}\left(\tau, \theta_{i}\right)+\tau, \theta_{i}\right)
$$

Furthermore, from the fact that NT imposes a constraint on the unilateral optimization by Home, it follows that $\bar{v}\left(\theta_{i}, \tau\right) \leq \hat{v}\left(\theta_{i}\right)$ with strict inequality if NT binds.

We assumed above that the environmental shock to which type $H$ is exposed is sufficiently large that it is globally efficient to levy higher total taxation on imports than on the domestic product - this amounts to the assumption that $t^{o}\left(\theta_{H}\right)>r^{o}\left(\theta_{H}\right)$. On the other hand, from a global welfare point of view, there is no reason to differentiate total taxation in case of a government of type $L: t^{o}\left(\theta_{L}\right)=r^{o}\left(\theta_{L}\right)$. Since the Home government disregards the adverse impact for foreign profit of $t$, and the favorable impact of $r$,

$$
r^{o}\left(\theta_{i}\right)>\hat{r}\left(\theta_{i}\right) \text { and } t^{o}\left(\theta_{i}\right)<\hat{t}\left(\theta_{i}\right)
$$

So far, we have not taken into consideration any strategic aspects of the choice of taxes for Home. But it is easily seen that it will be optimal for the Home government to set $\hat{r}\left(\theta_{i}\right)$ and $\hat{s}\left(\tau, \theta_{i}\right)$ regardless of whether it will face a complaint. This extreme feature of the model follows from two assumptions. First, there are no costs associated with taking part in, or losing, a dispute. Second, neither the probability of litigation, nor its outcome, is affected by 
the extent to which the two taxes diverge. The implications of relaxing these assumptions are further discussed in Section 8. The equilibrium behavior of the importing country government is hence to set $\hat{r}\left(\theta_{i}\right)<\hat{s}\left(\tau, \theta_{i}\right)$, regardless of whether it faces an environmental problem or not. In equilibrium, it will face litigation with certainty, and with probability $\Gamma_{i}$ have to change its taxes to the NT consistent taxes $r=s=\bar{z}\left(\tau, \theta_{i}\right)$, and with probability $1-\Gamma_{i}$ it can retain the preferred $\hat{r}\left(\theta_{i}\right)$ and $\hat{s}\left(\tau, \theta_{i}\right)$.

Finally, note that exposure to environmental problems does not remove a government's basic protectionist inclinations. Hence, the environmentally affected government's preferred taxation of the imported product does not only reflect its desire to combat the environmental problem but also its commercial interests.

\section{$5 \quad$ Tariff Negotiations}

A trade agreement consists of a pair of tariffs $\left(\tau, \tau^{*}\right)$, and an NT provision. Since governments cannot condition tariffs on environmental shocks, they have to negotiate tariffs that are efficient ex ante the realization of the environmental shocks. Due to the complete symmetry of the model, we focus on the bargaining outcome $\tau^{E}$ that maximizes $W$, but the negotiations of course also involve $\tau^{*}$, and the agreement will be such that $\tau^{E}=\tau^{* E}$, thus ensuring members an equal division of the ex ante gains from the agreement.

A tariff $\tau \geq \hat{\tau}\left(\theta_{i}\right)$ is almost by definition irrelevant for the importing country government of type $i$. For $\tau<\hat{\tau}\left(\theta_{i}\right)$, it will set $\hat{r}<\hat{s}$. If the complainant wins the ensuing litigation, and the importing country thus adjusts taxes to $r=s=\bar{z}\left(\tau, \theta_{i}\right)$, the resulting global welfare is

$$
\bar{w}\left(\tau, \theta_{i}\right) \equiv W\left(\bar{z}\left(\tau, \theta_{i}\right), \bar{z}\left(\tau, \theta_{i}\right)+\tau, \theta_{i}\right)
$$

while, in the opposite case, it is

$$
\hat{w}\left(\theta_{i}\right) \equiv W\left(\hat{r}\left(\theta_{i}\right), \hat{t}\left(\theta_{i}\right), \theta_{i}\right)
$$


The expected welfare with a government of type $i$ is then

$$
\tilde{w}\left(\tau, b, \theta_{i}\right)=\left\{\begin{array}{l}
\hat{w}\left(\theta_{i}\right) \text { for } \tau \geq \hat{\tau}\left(\theta_{i}\right) \\
\Gamma\left(\theta_{i}, b\right) \bar{w}\left(\tau, \theta_{i}\right)+\left[1-\Gamma\left(\theta_{i}, b\right)\right] \hat{w}\left(\theta_{i}\right) \text { for } \tau<\hat{\tau}\left(\theta_{i}\right)
\end{array} ; i=L, H .\right.
$$

Consider the implication for expected global welfare for government $i$ from reducing the tariff from $\tau=\hat{\tau}\left(\theta_{i}\right)$. The term $\left[1-\Gamma\left(\theta_{i}, b\right)\right] \hat{w}\left(\theta_{i}\right)$ in (11) is clearly not affected. To see the effect on $\bar{w}\left(\tau, \theta_{i}\right)$, note that when $\mathrm{NT}$ is binding for government $i$, the taxes will be $r=\bar{z}\left(\tau, \theta_{i}\right)$ and $t=s+\tau=\bar{z}\left(\tau, \theta_{i}\right)+\tau$. Since $\bar{w}\left(\hat{\tau}\left(\theta_{i}\right), \theta_{i}\right)=\hat{w}\left(\theta_{i}\right)$, it follows that ${ }^{15}$

$$
\begin{aligned}
\bar{w}_{\tau}\left(\theta_{i}, \hat{\tau}\left(\theta_{i}\right)\right) & =\frac{d}{d \tau} W\left(\bar{z}\left(\theta_{i}, \hat{\tau}\left(\theta_{i}\right)\right), \bar{z}\left(\theta_{i}, \hat{\tau}\left(\theta_{i}\right)+\hat{\tau}\left(\theta_{i}\right), \theta_{i}\right)\right. \\
& =\frac{d}{d \tau} \Pi^{*}<0 .
\end{aligned}
$$

That is, reducing the tariff slightly below $\hat{\tau}\left(\theta_{i}\right)$ increases the global welfare for government $i$. Since $\hat{\tau}\left(\theta_{H}\right)>\hat{\tau}\left(\theta_{L}\right)$, it is clear that the negotiated tariff will be set sufficiently low for NT to bind at least for the type $H$ government, i.e. "binds" in the sense that this government sets taxes $r<s$ :

Proposition 1 It is optimal to always set tariffs sufficiently low so that NT binds for governments that are environmentally affected, but not necessarily for purely protectionist governments.

It thus seems as if NT is environmentally unfriendly in a rather fundamental sense. This basic feature of NT stems from the fact that NT starts binding from the "wrong" side of the spectrum of types. Note, however, that it is not necessarily globally undesirable that these governments are caught by NT, since their taxes are differentiated by more than what is motivated by a concern for the environment. It is of global interest to counteract these protectionist motives.

\footnotetext{
${ }^{15}$ The sign follows from the fact that$$
\frac{d}{d \tau} \Pi^{*}=\Pi_{r}^{*} \bar{z}_{\tau}+\left(1+\bar{z}_{\tau}\right) \Pi_{t}^{*}
$$

where $\Pi_{r}^{*}>0, \bar{z}_{\tau}<0,1+\bar{z}_{\tau}>0$, and $\Pi_{t}^{*}<0$. 


\subsection{NT Binds for Both Types of Governments}

In this subsection and the next, we will characterize equilibrium tariffs and, to this end, we first introduce some notation. Let the fraction of governments of type $i$ be denoted $f\left(\theta_{i}\right)$. The implicit maximand for the tariff negotiations is then

$$
w^{E}(\tau, b) \equiv f\left(\theta_{L}\right) \tilde{w}\left(\tau, \theta_{L}, b\right)+f\left(\theta_{H}\right) \tilde{w}\left(\tau, \theta_{H}, b\right) .
$$

Also, let $\tau^{G}\left(\theta_{i}\right)$ be the optimal tariff from a global perspective if NT binds; hence $\tau^{G}\left(\theta_{i}\right) \equiv$ $\arg \max _{\tau} \bar{w}\left(\tau, \theta_{i}\right)$. It follows from the fact that $\bar{w}\left(\tau, \theta_{H}\right)=\hat{w}\left(\theta_{H}\right)$ for $\tau \geq \hat{\tau}\left(\theta_{H}\right)$ and $\bar{w}_{\tau}\left(\theta_{H}, \hat{\tau}\left(\theta_{H}\right)\right)<0$ that $\tau^{G}\left(\theta_{H}\right)<\hat{\tau}\left(\theta_{H}\right)$. There will thus be a range of $\tau$, from $\hat{\tau}\left(\theta_{H}\right)$ and downwards, for which global welfare is higher when NT is imposed than with an unconstrained tax setting. But we have assumed that it is preferable from a global point of view to let environmentally affected governments escape the NT obligation - at least for some $\tau$ - otherwise the adjudication problem would be trivial, since it would just be to rule in favor of the complainant in any case. Therefore, there will be a $\bar{\tau}^{G}\left(\theta_{H}\right) \in\left[0, \tau^{G}\left(\theta_{H}\right)\right)$ at which $\bar{w}\left(\tau, \theta_{H}\right)=\hat{w}\left(\theta_{H}\right)$, and below which the imposition of NT reduces global welfare for type $H$ governments.

First, consider the case where $\tau^{G}\left(\theta_{H}\right)<\hat{\tau}\left(\theta_{L}\right)$ - that is, where the optimal tariff for an environmentally affected government is lower than the tariff at which NT starts binding for the purely protectionist type of government. In this case, lowering $\tau$ below $\hat{\tau}\left(\theta_{H}\right)$ is optimal at least until we hit $\hat{\tau}\left(\theta_{L}\right)$. At this point, the NT constraint starts to bind for type $L$, so there is an additional reason for continuing to reduce the tariff until it hits $\tau^{G}\left(\theta_{H}\right)$. A small further reduction in $\tau$ below $\tau^{G}\left(\theta_{H}\right)$ would have a zero first-order effect in case of a type $H$ government, and a positive first-order effect in case of a type $L$ government. Hence, the negotiated tariff $\tau^{E}$ must in this case be lower than $\tau^{G}\left(\theta_{H}\right)$, and may equal or exceed zero, among other things depending on the relative frequency of the two types of governments. The larger the fraction of type $L$ governments, the more likely is the negotiated tariff to be zero. But NT binds in either case for both types; the outcome resembles a pooling equilibrium in 
this regard.

We can here distinguish between two subcases depending on whether $\tau^{E} \gtrless \bar{\tau}^{G}\left(\theta_{H}\right)$. In case $\bar{\tau}^{G}\left(\theta_{H}\right)<\tau^{E}$, global welfare is higher when NT binds than when it does not bind $\left(\bar{w}\left(\tau, \theta_{H}\right)>\hat{w}\left(\theta_{H}\right)\right)$. Taking the $(\hat{r}, \hat{t})$ equilibrium as a benchmark, the judicial errors will in this case be in the form of Type II errors - false negatives - committed in the fraction $1-\Gamma_{H}$ of disputes where the respondent prevails. In the opposite case, where $\tau^{E}<\bar{\tau}^{G}\left(\theta_{H}\right)$, there will be Type I errors - false positives - committed in the fraction $\Gamma_{H}$ of all disputes where the complainant prevails. Thus, we can decompose the equilibrium expected global welfare as

$$
\begin{aligned}
w^{E}\left(\tau^{E}, b\right)= & \underbrace{f\left(\theta_{L}\right) \Gamma\left(\theta_{L}, b\right) \bar{w}\left(\tau^{E}, \theta_{L}\right)}_{\text {NT correctly imposed }}+\underbrace{f\left(\theta_{L}\right)\left[1-\Gamma\left(\theta_{L}, b\right)\right] \hat{w}\left(\theta_{L}\right)}_{\text {Type II error: NT should be imposed }} \\
& +\underbrace{f\left(\theta_{H}\right) \Gamma\left(\theta_{H}, b\right) \bar{w}\left(\tau^{E}, \theta_{H}\right)}_{\text {Type II error if } \tau^{E} \in\left[\bar{\tau}^{G}\left(\theta_{H}\right), \tau^{G}\left(\theta_{H}\right)\right] ; \text { NT corr if } \tau^{E}<\bar{\tau}^{G}\left(\theta_{H}\right)}
\end{aligned}
$$

Judicial mistakes will thus be committed in case of both types of governments. In the case of purely protectionist governments, the error can only be to let through measures that should be declared illegal. But in case of environmentally affected governments, the qualitative nature of the errors will depend on the extent of trade liberalization. With modest liberalization, the adjudicator may erroneously accept differential taxation when NT should be imposed, and in case of more substantial liberalization, the errors take the form of imposing NT when differential taxation should be permitted.

Proposition 2 If NT binds for both types of government, the qualitative nature of the judicial errors in disputes with environmentally affected governments depends on the degree of tariff liberalization. Erroneous findings of NT violations are more likely, the more tariffs are liberalized.

Another way of phrasing this is to say that for modest trade liberalization, there is a discrepancy between the judicial decision that is beneficial for global welfare and the decision that 
is good for the environment. But when trade liberalization is sufficiently significant, the two interests become aligned.

The first-order condition determining the negotiated tariff when NT binds for both types of governments is:

$$
\begin{aligned}
w_{\tau}^{E}\left(\tau^{E}, b\right) & \left.=\sum f\left(\theta_{i}\right) \tilde{w}_{\tau}\left(\tau^{E}, \theta_{i}, b\right)\right) \\
& =f\left(\theta_{L}\right) \Gamma\left(\theta_{L}, b\right) \bar{w}_{\tau}\left(\tau^{E}, \theta_{L}\right)+f\left(\theta_{H}\right) \Gamma\left(\theta_{H}, b\right) \bar{w}_{\tau}\left(\tau^{E}, \theta_{H}\right) \\
& =0 .
\end{aligned}
$$

The first term (which is negative) represents the gain from imposing a lower tariff on the fraction $\Gamma\left(\theta_{L}, b\right)$ of type $L$ governments that is requested to respect NT. The second term (which is positive) gives the cost of pushing governments of type $H$ further from the level of $\tau$ that would maximize global welfare for this type. Hence,

Proposition 3 In situations where NT restricts both types of governments, the negotiated tariff will be lower than what is optimal from the point of view of environmentally affected governments.

\subsection{NT Only Binds for Environmentally Affected Governments}

We now briefly turn to the complementary case of the one considered in the previous subsection, and assume that $\hat{\tau}\left(\theta_{L}\right)<\tau^{G}\left(\theta_{H}\right)$. It is then once more possible that $\tau^{E}<\hat{\tau}\left(\theta_{L}\right)$, so that NT binds for both types of governments, and there is a form of pooling equilibrium. But it can also be optimal to set the tariff such that it only binds for type $H$, in which case it must be that $\tau^{E}=\tau^{G}\left(\theta_{H}\right) .{ }^{16}$ This is thus a form of separating equilibrium where only the

\footnotetext{
${ }^{16}$ The existence of this possibility is clear from the fact that at $\tau=\hat{t}\left(\theta_{H}\right)$, the welfare level $\hat{w}\left(\theta_{H}\right)$ can always be obtained, and a higher welfare can be obtained by somewhat reducing $\tau$, as we saw above. Hence, $\bar{w}\left(\theta_{H}, \tau^{G}\left(\theta_{H}\right)\right)>\hat{w}\left(\theta_{H}\right)$.
} 
high $\theta$ type is bound by NT. The equilibrium expected global welfare will then be

$$
w^{E}\left(\tau^{E}, b\right) \equiv f\left(\theta_{L}\right) \hat{w}\left(\theta_{L}\right)+\underbrace{f\left(\theta_{H}\right) \Gamma\left(\theta_{H}, b\right) \bar{w}\left(\tau^{G}\left(\theta_{H}\right), \theta_{H}\right)}_{\text {NT correctly imposed }}+\underbrace{f\left(\theta_{H}\right)\left[1-\Gamma\left(\theta_{H}, b\right)\right] \hat{w}\left(\theta_{H}\right)}_{\text {Type II error: NT not imposed }} .
$$

In this case, the NT net will only catch the environmentally affected governments, but will let type $L$ governments pass slip through. The reason why NT should still be imposed in this case is not because it is undesirable per se that type $H$ governments differentiate in their taxation. On the contrary, it is desirable because of the environmental shocks. But the problem is that when given the possibility for this, the governments do not only use it to combat the environmental problems, but also for protectionism, and NT helps prevent the latter. This would once more appear as a rather environment-unfriendly application of NT, since it would only have a bite for environmentally affected governments. But the tariff will now be ex ante optimal for environmentally affected governments.

\section{The Impact of the BoP}

The BoP is obviously only of importance to the extent that there is imperfect information concerning government types. Ideally, the test of whether a measure is "applied so as to afford protection" would have the property that

$$
\Gamma\left(\theta_{i}, b\right)=\left\{\begin{array}{l}
0 \text { for } i=H \text { and } \bar{w}\left(\tau^{E}, \theta_{H}\right)<\hat{w}\left(\theta_{H}\right) \\
1 \text { otherwise }
\end{array} .\right.
$$

But even with this full-information test would the outcome be inefficient relative to first best, as long as taxes are unilaterally set. First, taxes $r>s$ will not be caught by NT. But the resulting total taxation is still almost certain to be globally inefficient, since taxes will maximize national rather than global welfare. Second, in cases where taxes are correctly found to be globally undesirable, the corrective measure will induce the importing country to unilaterally set some $\bar{r}=\bar{s}$, but the decision on this common level will disregard the 
implications for Foreign. The introduction of imperfect information in the adjudication stage adds new problems from a global efficiency point of view, however.

\subsection{The BoP and Global Welfare}

As mentioned in the above, it is occasionally suggested that a lesser burden should be laid on regulating countries in environmental disputes in the WTO. To highlight the implication of such a change, we examine the impact of a shift in the BoP toward the complainant (which corresponds to a reduction in the parameter $b$ ) in the case where both types of governments are constrained by NT:

$$
\begin{aligned}
\frac{d}{d b} w^{E}\left(\tau^{E}(b), b\right) & =w_{b}^{E}\left(\tau^{E}(b), b\right) \\
& =\underbrace{f\left(\theta_{L}\right) \Gamma_{b}\left(\theta_{L}, b\right)\left[\bar{w}\left(\tau^{E}, \theta_{L}\right)-\hat{w}\left(\theta_{L}\right)\right]}_{\text {More Type II errors }}+\underbrace{f\left(\theta_{H}\right) \Gamma_{b}\left(\theta_{H}, b\right)\left[\bar{w}\left(\tau^{E}, \theta_{H}\right)-\hat{w}\left(\theta_{H}\right)\right]}_{\text {Fewer Type I errors/More Type II errors }} .
\end{aligned}
$$

Even in this extremely simple setting, the consequences of changing the allocation of the $\mathrm{BoP}$ are far from clear. The first term captures the fact that as the $\mathrm{BoP}$ is shifted toward the complainant, there will be more acquittals of purely protectionist governments, which tends to reduce welfare. But it will also reduce the propensity for environmentally affected governments to be found guilty of violating NT. The desirability of this latter effect will depend on the precise circumstances, however. When $\bar{w}\left(\tau^{E}, \theta_{H}\right)>\hat{w}\left(\theta_{H}\right)$, it will lead to more acquittals of environmentally affected governments that should be constrained by NT from a global point of view. The suggested shift of the BoP will in this case be unambiguously welfare reducing, increasing the number of type II errors in disputes involving both types of governments.

The case for the proposed shift in the $\mathrm{BoP}$ hence requires that $\bar{w}\left(\tau^{E}, \theta_{H}\right)<\hat{w}\left(\theta_{H}\right)$, so that it is globally - and not just nationally - undesirable to impose NT on environmentally affected governments. A number of factors interact to determine whether, in such an instance, a shift of the BoP toward the complainant (as has been suggested in the WTO context) is globally desirable. For instance, the level of the tariff affects the relative magnitude of expressions 
$\bar{w}\left(\tau, \theta_{L}\right)-\hat{w}\left(\theta_{L}\right)$ and $\bar{w}\left(\tau, \theta_{H}\right)-\hat{w}\left(\theta_{H}\right)$, but in an ambiguous fashion. What is clear though, is that the errors committed with regard to environmentally affected governments are of Type II if $\tau^{E}>\bar{\tau}^{G}\left(\theta_{H}\right)$, and of Type I in the opposite case. Hence, when the negotiated tariff is very low, it is more likely to be optimal to put a heavy BoP on the complainant.

Second, the impact of a change in the $\mathrm{BoP}$ is also affected by the relative magnitudes of terms $\Gamma_{b}\left(\theta_{L}, b\right)$ and $\Gamma_{b}\left(\theta_{H}, b\right)$, reflecting the difference in impact on the probability of judicial errors for the two types of governments. The larger the discrepancy between $\Gamma_{b}\left(\theta_{H}, b\right)$ and $\Gamma_{b}\left(\theta_{L}, b\right)$, the more likely it is to be optimal to put a heavy BoP on the complainant.

\subsection{The BoP and Negotiated Tariffs}

The negotiated tariff $\tau^{E}$ only affects governments when they lose disputes and are requested to set $r \geq s$. From the first-order condition (15), we know that $\bar{w}_{\tau}\left(\tau^{E}, \theta_{L}\right)<0<\bar{w}_{\tau}\left(\tau^{E}, \theta_{H}\right)$, so it will be globally optimal to set a higher tariff in case of an environmentally affected government compared to with a purely protectionist government. But since the tariff is negotiated ex ante the realization of the environmental shock, it will have to be set somewhere between the two levels, and the allocation of the $\mathrm{BoP}$ will affect this balancing. To gain some intuition for how, imagine temporarily that the reallocation of the BoP is sufficiently drastic that an environmentally affected government never loses a dispute. NT, and the tariff level, would then have no bite for this type of government, and the tariff should now be set solely so as to regulate the behavior of purely protectionist governments. Since, at the outset, the tariff was too high from the point of view of regulating these governments, it should be lowered. On the other hand, if the shift in the BoP were to imply that the purely protectionist government never lost a case, the logic would be the opposite, and the tariff would be increased as a result of the shift in the allocation of the BoP.

To more precisely see what determines the impact on the negotiated tariff, note that the sign of $d \tau^{E} / d b=-w_{\tau b}^{E} / w_{\tau \tau}^{E}$ is the same as the sign of $w_{\tau b}^{E}$, due to the second-order condition 
for an optimal tariff level, $w_{\tau \tau}^{E}<0$. Using the the first-order condition (15):

$$
\begin{aligned}
w_{\tau b}^{E}\left(\tau^{E}, b\right) & =f\left(\theta_{L}\right) \Gamma_{b}\left(\theta_{L}, b\right) \bar{w}_{\tau}\left(\tau^{E}, \theta_{L}\right)+f\left(\theta_{H}\right) \Gamma_{b}\left(\theta_{H}, b\right) \bar{w}_{\tau}\left(\tau^{E}, \theta_{H}\right) \\
& =f\left(\theta_{H}\right) \bar{w}_{\tau}\left(\tau^{E}, \theta_{H}\right) \Gamma\left(\theta_{H}, b\right)\left[\frac{\Gamma_{b}\left(\theta_{H}, b\right)}{\Gamma\left(\theta_{H}, b\right)}-\frac{\Gamma_{b}\left(\theta_{L}, b\right)}{\Gamma\left(\theta_{L}, b\right)}\right]
\end{aligned}
$$

where $\bar{w}_{\tau}\left(\tau^{E}, \theta_{L}\right)<0<\bar{w}_{\tau}\left(\tau^{E}, \theta_{H}\right)$ by the first-order condition (15). The sign of $d \tau^{E} / d b$ is hence the same as that of the term in brackets in this expression. Since $0<\Gamma\left(\theta_{H}\right)<\Gamma\left(\theta_{L}\right)$, and $\Gamma_{b}\left(\theta_{i}, b\right)<0$, it follows that a sufficient but not necessary condition for $d \tau^{E} / d b<0$ is that $\Gamma_{b}\left(\theta_{H}, b\right) \leq \Gamma_{b}\left(\theta_{L}, b\right)$. An alternative way of highlighting what determines the direction in which the tariff changes is to rewrite (15) as

$$
\frac{\bar{w}_{\tau}\left(\tau^{E}, \theta_{H}\right)}{\bar{w}_{\tau}\left(\tau^{E}, \theta_{L}\right)}=-\frac{f\left(\theta_{L}\right)}{f\left(\theta_{H}\right)} \frac{\Gamma\left(\theta_{L}, b\right)}{\Gamma\left(\theta_{H}, b\right)} .
$$

A reallocation of the $\mathrm{BoP}$ will thus reduce negotiated tariffs if and only if it increases the ratio $\frac{\Gamma\left(\theta_{L}, b\right)}{\Gamma\left(\theta_{H}, b\right)}$. We will say that such a change as makes the adjudication more targeted, since it becomes relatively more apt at capturing the purely protectionist governments relative to capturing environmentally affected governments.

Proposition 4 A reallocation of the BoP that makes adjudication more (less) targeted will reduce (increase) negotiated tariffs.

Above we defined a shift of the BoP toward the complainant as a measure that reduces the probability for the complainant of prevailing against both types of importing country governments (that is, $\Gamma_{b}\left(\theta_{i}, b\right)<0$ ). This definition does not restrict the direction in which the shift affects the ratio $\Gamma\left(\theta_{L}, b\right) / \Gamma\left(\theta_{H}, b\right)$, however. But it is straightforward to identify sufficient circumstances under which the shift in the makes adjudication more targeted. First, it is clear from the above that a sufficient but not necessary condition for this is that $\Gamma_{b}\left(\theta_{L}, b\right) \leq \Gamma_{b}\left(\theta_{H}, b\right)$.Second, it is straightforward to see that a reallocation of the BoP that only reduces the probability that the complainant will prevail against an environmentally affected government $\left(\Gamma_{b}\left(\theta_{L}, b\right)=0\right.$, and $\left.\Gamma_{b}\left(\theta_{H}, b\right)<0\right)$, will be targeted. 
Finally, consider a linear version of $\Gamma$ :

$$
\Gamma\left(\theta_{i}, b\right) \equiv a_{i}-k_{i} b \text { for } b<a_{H} / k_{H},
$$

where $a_{i}<1$, and $b \geq 0$. To fulfil the basic property $\Gamma\left(\theta_{L}, b\right)>\Gamma\left(\theta_{H}, b\right)$, it is required that $a_{L}>a_{H}$, and that $a_{L} / k_{L}>a_{H} / k_{H} . \Gamma\left(\theta_{i}, b\right)$ is differentiable w.r.t. $b$ for $b \in\left(0, a_{H} / k_{H}\right)$. With this specification, a change in $b$ that reduces the probability for the complaining country of prevailing in both types of disputes - an increase in $b$ - increases the ratio $\Gamma\left(\theta_{L}, b\right) / \Gamma\left(\theta_{H}, b\right)$ for $b<a_{H} / k_{H}$ :

$$
\frac{d}{d b}\left(\frac{a_{L}-k_{L} b}{a_{H}-k_{H} b}\right)=\frac{k_{H} k_{L}}{\left(a_{H}-b k_{H}\right)^{2}}\left(\frac{a_{L}}{k_{L}}-\frac{a_{H}}{k_{H}}\right)>0 .
$$

The shift in the BoP will thus unambiguously make adjudication more targeted in this case.

These examples depict what seem to be reasonable situations, but they do not suffice to exclude the possibility that the tariff will increase, in particular not for certain ranges of $\tau$. It takes a more specific change in the allocation of the $\mathrm{BoP}$ in order to obtain unambiguous conclusions concerning the impact for the negotiated tariff.

\subsection{The BoP and Environmental Damage}

It is tempting to believe that the environment is better protected the more countries purporting to regulate the environment enjoy the benefit of the doubt in environmental disputes. To establish whether this is indeed the case, consider first the case where only environmentally affected governments are constrained by NT. The negotiated tariff will then be $\tau^{E}=\tau^{G}\left(\theta_{H}\right)$ and it is thus unaffected by the BoP. Hence, it is clear that the shift in the BoP toward the complainant in this case has the expected effect of reducing environmental problems, by reducing the number of cases where governments subjected to environmental shocks are forced to abide by NT.

Turn next to the case where NT binds for both types of governments. Recalling that there is no damage in the case of an type $L$ government $\left(\theta_{L}=0\right)$, the expected level of 
environmental damage $K$ is:

$$
K\left(b, \tau^{E}(b)\right) \equiv f\left(\theta_{H}\right) \theta_{H}\left\{\Gamma\left(\theta_{H}, b\right) \bar{M}\left(\tau^{E}(b), \theta_{H}\right)+\left[1-\Gamma\left(\theta_{H}, b\right)\right] \hat{M}\left(\theta_{H}\right)\right\}
$$

where $\bar{M}\left(\tau^{E}(b), \theta_{H}\right) \equiv M\left(\bar{z}\left(\theta_{H}, \tau^{E}(b)\right), \bar{z}\left(\theta_{H}, \tau^{E}(b)\right)+\tau^{E}(b)\right)$ and $\hat{M}\left(\theta_{H}\right) \equiv M\left(\hat{r}\left(\theta_{H}\right), \hat{t}\left(\theta_{H}\right)\right)$. As can be seen, the expected environmental damage depends on both the allocation of the $\mathrm{BoP}$, and the negotiated tariff level. The first-order impact of a change in $b$ is

$$
\begin{aligned}
\frac{d}{d b} K\left(\tau^{E}(b), b\right)= & f\left(\theta_{H}\right) \theta_{H} \Gamma_{b}\left(\theta_{H}, b\right)\left[\bar{M}\left(\tau^{E}(b), \theta_{H}\right)-\hat{M}\left(\theta_{H}\right)\right] \\
& +f\left(\theta_{H}\right) \theta_{H} \Gamma\left(\theta_{H}, b\right) \bar{M}_{\tau}\left(\tau^{E}(b), \theta_{H}\right) \frac{d \tau^{E}}{d b} .
\end{aligned}
$$

The first term on the right-hand side captures a within-dispute effect: there will be a tendency toward fewer disputes where complaining exporting countries win and thus, toward reduced imports (since $\Gamma_{b}<0$, and $\bar{M}\left(\tau, \theta_{H}\right)>\hat{M}\left(\theta_{H}\right)$ ). This will tend to reduce the environmental damage from imports, as expected.

The second term captures the induced effect of the allocation of the BoP for environmental damage through a change in the negotiated tariff and thus imports. Since $M_{r}>0, M_{t}<0$, and $-1<\bar{z}_{\tau}<0$, it follows that

$$
\bar{M}_{\tau}=M_{r} \bar{z}_{\tau}+M_{t}\left(1+\bar{z}_{\tau}\right)<0,
$$

that is, the combined consequences of the direct effect of a tariff reduction and the induced changes in taxes is to increase imports.

Taking into account the findings in the previous section:

Proposition 5 If NT binds for both types of governments, a shift of the BoP toward complainants reduces environmental damage by increasing the fraction of disputes where environmentally affected countries can regulate freely. But if this shift makes the adjudication more (less) targeted, it will tend to increase (reduce) environmental damage due to an induced increase (reduction) in trade. 
Finally, note that there is no first-order welfare impact from the induced tariff reduction since the tariff is set optimally; $w_{\tau}^{E}=0$. The first-order welfare impact of the BoP consists of the effects captured in expression (18).

\section{The Costs of Environmental Shocks}

NT may constrain environmentally affected governments in their taxation. It seems intuitively plausible that when this is globally undesirable, the cost of such mistakes should be particularly high when environmental shocks are particularly severe $\left(\theta_{H}\right.$ is large). This intuitively appealing notion is at best only partly correct, and for a rather simple reason. To see why, suppose that the environmental shock is such that if Type I errors can be committed, and if committed, the importing country sets NT-consistent taxes $r^{\prime}=s^{\prime}=\bar{z}^{\prime}$ that increase imports. If so, the environmental problem is worsened as a result of the imposition of NT, along the lines of the intuitive reasoning above, due to the expansion in trade.

Now instead consider an extremely severe environmental shock, say as in an EC-Asbestos scenario. If unconstrained, the Home government would set taxes $r^{\prime \prime}$ and $s^{\prime \prime}$ that completely choked off imports. If there is now a Type I error, and Home is requested to set NTcompatible taxes, Home would set an NT-compatible tax that continued to completely keep imports out. But this would imply that it also kept the Home product out. Hence, when the environmental hazard is severe enough, the cost of the judicial mistake of disallowing differential taxation does not take the form of environmental damage - the environmental hazard will in any event be fully counteracted. Instead, the cost stems from lost domestic producer and consumer surplus from the unnecessary shutdown of domestic production. Moreover, since environmental shocks cannot do more than wipe out these surpluses, there is an upper bound on the cost of erroneously not allowing countries to differentiate their taxation.

Proposition 6 For a given tariff, the social costs of very severe environmental hazards take 
the form of lost domestic producer and consumer surplus, rather than environmental damage.

\section{Extensions}

This section will briefly discuss implications of extending or modifying some of the assumptions underlying the above model. Each of these changes could substantially enrichen the analysis, but would also substantially complicate it.

\subsection{Litigation Costs}

The above model assumed that there are no costs associated with litigation. This highly simplifying assumption implies that some of the properties of the equilibrium will seem extreme. In particular, an exporting country stands nothing to lose from complaining whenever $r<s$, so in all such situations there will be a complaint, and the importing country stands nothing to lose from setting such taxes, and possibly losing a resulting dispute. To see why, assume that Foreign government bears a cost $c^{*}$, and the importer government a cost $c$, when participating in a dispute. Naturally, $c$ and $c^{*}$ can capture the direct administrative costs of participating in dispute settlement proceedings, but might also be interpreted as costs arising from an erosion of the parties' confidence in the agreement. As before, assume that for a given tariff, the importing country first sets taxes, and the exporting country then decides whether to litigate, if $r<s$. One might also naturally have a third stage where the importing country decides whether to act as a respondent, or accept the complaint, but this will be disregarded here.

First, consider the Foreign government's decision, assuming mainly for notational convenience that Foreign knows Home's type. Foreign will challenge the pair $r<s$ iff

$$
\gamma \bar{\pi}^{*}(\tau, \theta)+(1-\gamma) \pi^{*}(r, s+\tau)-c^{*}>\Pi^{*}(r, s+\tau)
$$


or

$$
\bar{\pi}^{*}(\tau, \theta)-\Pi^{*}(r, s+\tau)>\frac{c^{*}}{\Gamma(\theta, b)} .
$$

To reduce the number of cases to consider, let $c^{*}$ be sufficiently small such that this inequality is fulfilled for $\left(\hat{r}\left(\theta_{i}\right), \hat{s}\left(\tau, \theta_{i}\right)\right)$ for all $\tau<\hat{\tau}\left(\theta_{L}\right)$; this ensures that if Home were to set its mostpreferred taxes, there would always be a complaint.

For $\tau$ slightly lower than $\hat{\tau}(\theta), \bar{\pi}^{*}(\tau, \theta)$ is only slightly larger than $\Pi^{*}(\hat{r}(\theta), \hat{t}(\theta))$, and it would thus not be worthwhile for Foreign to litigate, despite $\hat{r}<\hat{s}$. Hence, there will be a range of tariffs $\left(\tau_{C}, \hat{\tau}\right)$ in which Home can violate NT, but still not be contested by Foreign.

For $\tau<\tau_{C}$, Foreign will definitely complain if taxes are set at $\left(\hat{r}\left(\theta_{i}\right), \hat{s}\left(\tau, \theta_{i}\right)\right)$. But among all taxes that trigger complaints, these are the taxes to choose, since the probability of winning the resulting dispute is unaffected by the level of the taxes (this assumption is discussed below). The alternative is to set taxes so as to avoid triggering a complaint. To this end, Home would have to set $s<\hat{s}\left(\theta_{i}\right)$ and/or $r>\hat{r}\left(\theta_{i}\right)$ since both of these actions would increase $\pi^{*}$, and it would presumably choose a combination of both. Let $\left(r^{\prime}(\tau, \theta), s^{\prime}(\tau, \theta)\right)$ be the solution to

$$
\max _{r, s} V(r, s+\tau, \theta) \text { s.t. } \Gamma(\theta, b)\left[\bar{\pi}^{*}(\tau, \theta)-\Pi^{*}(r, s+\tau)\right] \leq c^{*}
$$

and let $v^{\prime}(\theta, \tau) \equiv V\left(r^{\prime}(\tau, \theta), s^{\prime}(\tau, \theta)+\tau, \theta\right)$ and $\pi^{* \prime}(\tau, \theta) \equiv \Pi^{*}\left(r^{\prime}(\tau, \theta), s^{\prime}(\tau, \theta)+\tau\right)$. Setting $\left(r^{\prime}, s^{\prime}\right)$ is always better from the Home country's point of view than the NT outcome, since with (almost) NT compatible taxes, the LHS of the inequality would be close to zero, and the inequality would thus be fulfilled for $c^{*}>0$. Home will thus set taxes so as to trigger a complaint iff

$$
\gamma \bar{v}(\tau, \theta)+[1-\gamma] v^{\prime}(\theta, \tau)-c \geq v^{\prime}(\theta, \tau)
$$

that is, iff

$$
v^{\prime}(\tau, \theta)-\bar{v}(\tau, \theta) \geq \frac{c}{1-\Gamma(\theta, b)}
$$

The tariff level affects this condition in a rather complex manner. It does not seem possible 
to say anything about the relative rate at which the two expressions are affected and hence, we do not know whether a lower $\tau$ makes it more or less likely that (26) is fulfilled. ${ }^{17}$

As can be seen, when litigation costs are taken into consideration, matters become more complicated analytically, causing the decisions of the importing country and the exporting country to be strategically interlinked: when deciding whether to discriminate, the importing country must take into consideration the probability that it will face litigation, since losing a litigation is costly because of the litigation costs. The probability that the exporting country will complain in turn depends on how much government welfare will increase, if the complaint is successful. This gain will be the difference between export revenues in the situation where NT binds, and where the importing country is allowed to continue with its contested tax setting. Hence, by not deviating too far from what would be prescribed by NT, an importing country may weaken the incentives for the exporting country to complain.

Some conclusions can be drawn, however. First, a general observation is that litigation costs can explain why importing countries do not always set the unconstrained optimal taxes regardless of whether this will provoke complaints, and they can explain why exporting countries do not complain in each instance where NT is violated (and further extending the analysis, also why respondents choose not to contest complaints).

Second, as can be seen from (26), for $c$ sufficiently large, it will never be worthwhile to trigger a complaint. ${ }^{18}$ In this case, Home would set discretionary taxes $\left(\hat{r}\left(\theta_{i}\right), \hat{s}\left(\theta_{i}\right)\right)$ for $\tau \in\left(\tau_{C}, \hat{\tau}(\theta)\right)$, while for lower tariffs, it would choose $\left(r^{\prime}(\tau, \theta), s^{\prime}(\tau, \theta)\right)$. In this case, NT would be violated regardless of $\tau$. But NT would still have a disciplining effect, despite never being invoked in a dispute. Hence, the off-equilibrium threat of being requested to impose NT deters too pronounced differential taxation for $\tau<\tau_{C}$.

\footnotetext{
${ }^{17}$ For instance, if $\tau=0, \bar{\pi}^{*}$ is large, and $\bar{v}$ is small. Home then has to offer Foreign a very attractive pair $\left(r^{\prime}, s^{\prime}\right)$ to dissuade Foreign from complaining (i.e., to make $\pi^{* \prime}$ sufficiently attractive relative to $\left.\bar{\pi}^{*}\right)$. But this will make $v^{\prime}$ small and thus, it is not clear how $v^{\prime}-\bar{v}$ is affected by setting $\tau=0$.

${ }^{18} \mathrm{We}$ could further refine the analysis by allowing Home to immediately accept the complaint, and thereby save some or all of the cost $c$.
} 
Third, if $c$ is sufficiently small, (26) will always be fulfilled, and Home always sets the discretionary taxes. There will then be no complaint for $\tau \in\left(\tau_{C}, \hat{\tau}(\theta)\right)$, while for $\tau<\tau_{C}$ there will always be litigation. Costs of judicial mistakes will arise once more, but now there is an additional inefficiency, since litigation now imposes costs on both parties.

Finally, in addition to the effects discussed in Section 6, the BoP will now also affect the likelihood that disputes arise and it will affect the tax setting. In particular, a shift of the BoP toward the exporting country (an increase in b) will reduce the set of taxes for which (24) holds, and it will increase the likelihood that (26) is fulfilled. That is, it will tend to increase the incentives to set discretionary taxes, and it will simultaneously reduce the incentives to complain. ${ }^{19}$

\subsection{The Extent of Tax Differentiation Affects $\Gamma$}

GATT/WTO adjudicators have occasionally interpreted a significant difference in taxes as a sufficient verification of a violation of Art. III (see [10]). A natural extension of the model would therefore be to assume that $\Gamma$ increases in $s-r$. This would create an incentive for the importing country government to limit the extent of its differentiation. Similarly to the case of litigation costs, it would imply that NT has an impact even if it is not imposed in equilibrium through dispute settlement. A similar phenomenon would arise if the magnitude $s-r$ affected the probability that the differential taxation is detected by the exporting country, as seems likely to be the case.

\footnotetext{
${ }^{19}$ Another likely impact of litigation costs is to increase the incentives for the parties to reach a pre-trial settlement. In the WTO, this is the preferred method of settlement, and the Dispute Settlement mechanism provides for a compulsory period of negotiation before a panel is established. For a recent theoretical analysis, see [15].
} 


\subsection{More Sophisticated Adjudicators}

In the above analysis, we did not model how the adjudicator forms its view concerning the nature of the preferences of the government in the importing country and we thus excluded the possibility for countries of strategically using information asymmetries, and for the adjudicator to use its understanding of the incentives facing different types of countries. An alternative approach would be to model interaction as a game of imperfect information, in which adjudicators as far as possible rationally deduce information from their observations. Following a standard approach, it would be assumed that the adjudicator has full information concerning the structure of the welfare function, the relative frequency of different types of governments, etc, but it does not observe the realization of $\theta$ for the incumbent government. With its knowledge of welfare functions, the adjudicator could then potentially infer the value of $\theta$ that must have generated the observed taxes $\hat{r}$ and $\hat{s}$. Since governments of type $L$ would lose from being identified, they would have incentives to try to mimic the behavior of type $H$ governments, and there may potentially be a pooling equilibrium with all governments taxing in the same manner in equilibrium. But governments of type $H$ will want to distinguish themselves from type $L$ governments, and may under certain circumstances be able to signal their identity in a separating equilibrium. Etc.

This approach has its advantages and disadvantages as compared to the one employed in this paper. An advantage of the approach we have used, besides probably being analytically more simple, is that the outcome of the decision process is less sensitive to the assumed details of the interaction. A disadvantage, as with all reduced-form representations, is, of course, the arbitrariness regarding assumed properties. However, it should be noted that the formulation of such a game is not a trivial matter, if the aim is to capture salient features of actual environmental disputes. The recent WTO dispute EC-Biotech Products (the "GMO dispute") may illustrate the magnitude of the problem. In this dispute, the written verdict - the panel report - comprises more than 1000 pages. Just the Table of Contents of the Panel report runs over almost 40 pages. The parties submitted over 3100 documents, some 
of which containing more than 100 pages. The dispute only partly dealt with Art. III GATT, but it does seem indicative of the potential complexity of environmental disputes. It is far from clear how the essence of such a dispute could be distilled to the degree that it can be meaningfully analyzed within a formalized game of imperfect information. At the same time, it does seem reasonable to believe that the outcome of such a dispute is likely to partly depend on the true motives for the regulation and the general stance on the BoP; hence the approach taken here. Analyzing environmental NT disputes as games of asymmetric information might well bring important insights that cannot be achieved within the current framework. But it is not a trivial task if to be done in a meaningful way, and it must be left to future work.

\section{Conclusions}

Unilaterally environmental policies cause a fundamental problem for the design of trade agreements: it is often very difficult for adjudicators to determine the true rationale for policies that are allegedly pursued to protect the environment, but that at the same time protect commercial interests. The first line of defense in the WTO against protectionist use of domestic instruments is the NT provision in Art. III GATT, which jointly with the General Exceptions clause in Art. XX GATT shape the basic scope for unilateral environmental in for WTO members. But the practical ambit of these provisions is importantly affected by the allocation of the BoP.

The purpose of this paper is to shed light on the likely functioning of NT in environmental trade disputes, focusing on the interaction between trade liberalization and the design of the NTprovision, and in particular on the role of the allocation of the BoP. The paper makes the following main observations:

1. NT has a certain "environmentally unfriendly" bias in that when it binds, it definitely constrains governments facing environmental shocks, but not necessarily purely protec- 
tionist governments;

2. the extent to which judicial errors take the form of false acquittals of protectionist measures or of wrongful findings of discrimination, depends on the interaction between the degree of tariff liberalization and the severity of environmental shocks;

3. when environmental shocks are sufficiently severe, the cost of a wrongful imposition of NT does not take the form of environmental damage, but of lost consumer and producer surpluses;

4. a targeted (as defined above) reallocation of the BoP will enhance tariff liberalization; and

5. a shift of the BoP toward complaining countries will have a direct "with-in dispute" effect of reducing expected environmental damage by increasing the probability for environmentally affected countries to prevail. But if the shift is targeted, it will also indirectly increase expected environmental damages by inducing more imports.

The general conclusion is thus that there seems to be a tension between NT, as it is likely to be implemented under the WTO Agreement, and environmental concerns. But this concern may be misguided when it focuses on the damage of large environmental shocks. It also appears as if a general shift of the $\mathrm{BoP}$ in environmental disputes toward complaining countries is not a suitable remedy for any such problem.

\section{References}

[1] Horn, Henrik. 2006. "National Treatment in the GATT". American Economic Review $96(1), 394-404$.

[2] Saggi, Kamal and Nese Sara. 2008. "National Treatment at the WTO: The Roles of Product and Country Heterogeneity." International Economic Review 49(4), 1365-1394. 
[3] Horn, Henrik, Giovanni Maggi and Robert W. Staiger. 2009. "The GATT as an Endogenously Incomplete Contract." American Economic Review (forthcoming).

[4] Baksi, Soham and Amrita Ray Chaudhuri. 2008. "Transboundary Pollution, Trade Liberalization, and Environmental Taxes." Tilburg Law and Economics Center Discussion Paper No. 2008-033.

[5] Gulati, Sumeet and Devesh Roy. 2008. "National Treatment and the Optimal Regulation of Environmental Externalities." Canadian Journal of Economics 41(4), 1445-1471.

[6] Ferrara, Ida, Paul Missios and Haliz Murat Yildiz. 2008. "Trading Rules and the Environment: Does Equal Treatment Lead to a Cleaner World?" Journal of Environmental Economics and Management (forthcoming).

[7] Maggi, Giovanni and Robert W. Staiger. 2008. "On the Role and Design of Dispute Settlement Procedures in International Trade Agreements." NBER Working Paper No. W14067.

[8] Ederington, Josh. 2009. "Negotiating over Environmental Policy in Trade Agreements." University of Kentucky (mimeo).

[9] Horn, Henrik and Petros C. Mavroidis. 2004. "Still Hazy after All These Years: The Interpretation of National Treatment in The GATT/WTO Case-Law On Tax Discrimination." Journal of International Economic Law.

[10] Horn, Henrik and Petros C. Mavroidis. 2009. "The Burden of Proof in Environmental Disputes in the WTO: Legal Aspects". European Energy and Environmental Law Review 17(2) (forthcoming).

[11] Shin, Hyun Song. 1998. "Adversarial and Inquisitorial Procedures in Arbitration." Rand Journal of Economics 29(3), 84-95. 
[12] Sanchirico, Chris W.. 2008. "A Primary Activity Approach to Proof Burdens." The Journal of Legal Studies 37(1), 273-314

[13] Horn, Henrik and Petros C. Mavroidis. 2009. "The Permissible Reach of National Environmental Policies." Journal of World Trade 42(6), 1107-1178

[14] Bagwell, Kyle and Robert W. Staiger. 1999. "An Economic Theory of the GATT." American Economic Review 89(1), pp. 215-248.

[15] Beshtar, Mostafa . 2008. "Third-Party-Assisted Renegotiation of Trade Agreements." Purdue University (mimeo). 